Article

\title{
Numerical Assessment of Shear Boundary Layer Formation in Sewer Systems with Fluid-Sediment Phases
}

\author{
Yang Ho Song $\left.{ }^{1} \mathbb{(}\right)$, Jin Gul Joo ${ }^{2}$, Jung Ho Lee ${ }^{1}$ and Do Guen Yoo ${ }^{3, *}$ \\ 1 Department of Civil and Environmental Engineering, Hanbat National University, Daejeon 34158, Korea; \\ syho@daum.net (Y.H.S.); leejh@hanbat.ac.kr (J.H.L.) \\ 2 Department of Civil and Environmental Engineering, Dongshin University, Naju 58245, Korea; \\ jgjoo@dsu.ac.kr \\ 3 School of Civil and Environmental Engineering, The University of Suwon, Gyeonggi-do 18323, Korea \\ * Correspondence: dgyoo411@suwon.ac.kr; Tel.: +82-31-229-8676
}

Received: 27 March 2020; Accepted: 5 May 2020; Published: 8 May 2020

check for updates

\begin{abstract}
Numerical and empirical studies of soil slurry transport and deposition in urban stormwater sewers are few, presumably due to the difficulty of direct observation of soil slurry flow in stormwater pipes. Slurry in a sewer system includes both suspended load and bedload, but few studies have attempted to demarcate these two components. A boundary layer is a crucial determinant of sediment transport capacity. Stormwater runoff enters the sewer in turbulent flow, mostly mixed with soil slurry generated by rainfall. In this paper, we attempt analysis using ANSYS Fluent commercial CFD software. We describe the development of a numerical analytical methodology capable of predicting the flow of soil slurry in stormwater pipes, and propose a method for estimating the sediment-flow boundary layer. Using this model, we simulated stormwater runoff with a large content of soil slurry during a rainfall event. We investigated soil slurry transport and predict the formation of shear boundary layer by varying the inlet conditions (volume of soil slurry entering the stormwater sewer system) and by analyzing the flow velocity field and soil slurry volume fraction in the pipes under various experimental flow conditions. Based on the shear and settling velocity of sediment particles, we propose criteria for the formation of a shear boundary layer in stormwater pipes.
\end{abstract}

Keywords: slurry; boundary layer; transportation; numerical analysis; shear velocity; settling velocity; sewers

\section{Introduction}

South Korea's total annual precipitation is high, but highly concentrated in the summer months, with storms producing excessively concentrated local rainfall events [1-3]. Heavy rains in the summer transport large amounts of soil and floating debris, such as twigs, driftwood, and pebbles, which can block drainage pipes and thus cause landslides or floods. Mountainous regions affected by high rates of sediment transport often suffer damage caused by sedimentation of soils and debris in drainage pipes. Sedimentation exceeding the rate of subsidence results in overflow, increasing the risk of damage due to landslides or floods $[4,5]$. To prevent such damage, drainage pipe design must be informed by an understanding of flow characteristics, taking account of the sedimentation of soil and debris in the drainage network. Slurry transport through the pipeline causes various problems; for example, deposition of slurry solids lowers the performance and efficiency of the entire drainage system [6-9].

During a heavy rainfall event, soil slurry is detached from the base surface by rainwater and flows with it into the drainage system. Debris, including soil sludge, undermines the discharge capacity of a 
drainage pipe, and reduces its designed discharge capacity. The resultant slowing of stormwater flow leads to overflow, thus incurring flood damage.

Flooding in urban areas does not result from a single cause, but from the complex interaction of various factors. Given this complexity, it is important to closely examine the interaction between flooding-causing processes in order avert the risk of flooding. Of particular importance among them are phenomena arising from sedimentation-induced loss of water discharge capacity of pipes. To ensure adequate maintenance of the drainage network, it is necessary to understand sedimentation in pipes during and after heavy rainfall events [10-14].

Slurry flow within a stormwater pipe involves processes of transport and deposition [15]. Transport phenomenon can be defined as the movement of solid particles in a fluid flowing through stormwater pipelines [16]. Transport of slurry is a complex phenomenon involving physical, chemical, and biological processes. The specifications for stormwater pipe design define the minimum designed flow rate for preventing sedimentation in pipes. Understanding sedimentation in stormwater pipes is crucial for pipeline maintenance. In this regard, studies of sediment behavior in unpressurized sewer systems have been proposed [17-20]. Theoretical and analytical groundwork to support related research and design is urgently needed [21].

Previous work on slurry transport includes the development of a relational equation using critical velocity values, and the quantification of slurry transport and deposition by specifying threshold values [22,23]. These studies have made important contributions to the prediction of sediment transport behavior. They have also contributed to the determination of discharge capacity in waterway design by taking into account the amount of sediment based on estimates of riverbed erosion [24,25]. Other studies attempt to express the transport of riverbed sediments. [26-30]. All previously proposed models tend to provide similar results for non-cohesive particles of uniform diameter in a steady flow. Most of the earlier research, however, concerns streams; very few earlier studies examine the flow characteristics of fluids in stormwater pipes.

Existing empirical equations for stream flow can be applied to the flow in stormwater pipes with necessary adjustments of hydraulic characteristics. Of particular importance in this regard are the internal flow characteristics. Since the flow in a stormwater sewer system has different dynamics from the flow of a stream, accurate prediction cannot be achieved from stream-based models. For example, the flow distribution of velocity the internal flow of urban sewer conduits are completely different from that of a river, making it difficult to obtain accurate predictions. For this purpose, existing empirical equations based on flow along a river may be applicable if modified according to the hydraulic features of urban sewer conduits [31,32]. Moreover, to be kept free from sediment, stormwater pipe design usually takes into account the flow velocity and shear stress; however, constant values of the latter are applied as design criteria.

This study examined the flow characteristics in stormwater pipes based on a two-phase flow of soil slurry. Unlike earlier studies [31,32], this study focused on the flow boundary layer between sediment and water. Shear stress and shear velocity (also called friction velocity) are two fundamental parameters for the mathematical treatment of determining a flow boundary layer. Shear velocity, also called friction velocity, is a form by which shear stress may be re-written in units of velocity, to a velocity that relates shear between layers of flow. Sedimentation due to deposition occurs when the bottom shear stress drops below the critical (threshold) level for sediment transport. That is, a very large shear stress develops near the pipe bottom or wall, and only sediment particles that have a shear strength sufficient to withstand this shear stress are deposited on the pipe bottom to form a sediment layer.

This study extends the results of previous studies [31,32]. It aimed to investigate the phenomena of slurry transport and deposition in stormwater pipes under different inflow conditions, and to analyze the sediment/fluid boundary layer generated in these conditions. It also sheds light on the two-phase flow involving soil slurry, a phenomenon that, due to the difficulties associated with its direct observation, remains poorly understood. Here, we describe our study of the flow characteristics 
in different conditions of flow velocity and soil slurry volume, and, based on the interrelationship between the latter, we developed a numerical analysis model that simulates sedimentation of soil slurry in stormwater pipes.

\section{Materials and Methods}

\subsection{Numerical Analysis}

Two-phase flows involving solid particles can cause an unstable nature, promoting mixing and energy dissipation which can cause transport problems. The flow properties of unsteady flow are very important for high concentration slurry transportation. There are two main approaches to numerical modeling that account for these unstable flows [33-35], such as a fluid flow containing solid particles: the Eulerian approach, in which solid particles are assumed to be a continuous, fluid-like medium; and the Lagrangian approach, in which Newton's law of motion is applied to solid particles. In the Eulerian approach, the different phases treated as a continuum can be further classified into a single-fluid model that applies continuity equations, momentum equations, and particle component conservation equations by handling a mixture of soil and water as a fluid, and a two-phase separation model that applies the laws of conservation to the soil particles and the fluid. The concept of phase volume fraction was introduced, since the volume of phases cannot be occupied by other phases [31-33]. In this study, a two-phase flow in which fluid and soil are introduced was assumed. It was assumed that in the two-phase flow in which fluid and soil were introduced, flow conditions did not change and no deformed flow occurred. In this process, the full condition was considered and the sediment transport characteristics of the pressure pipeline were examined. This method can reduce calculation time and carry out an optimal solution through repeated calculations [36-39].

In this study, we carried out numerical analysis using ANSYS Fluent Workbench 13.0 [40]. ANSYS Fluent (FLUENT Inc.) is a program for modeling fluid flow using two-dimensional (2D) and three-dimensional (3D) finite-volume numerical procedures based on a graphical user interface (GUI) for hydrodynamics (fluid dynamics, heat transfer), and chemical reactions. Capable of performing comprehensive tasks including preprocessing, calculation, and postprocessing required for computational fluid dynamics (CFD) analysis, ANSYS Fluent comprises the Gambit (preprocessing), Tgrid (fluent meshing), and FLUENT (calculation and postprocessing) programs. The aforementioned 2D numerical models are unstructured grid-calculation programs that support tetrahedron, hexahedron, prism, pyramid, and polyhedral grids using the finite-volume method (FVM) to perform modeling of various complex shapes, and to provide numerical analysis for field-specific applications. In this study, boundary conditions of inlet velocity were taken as the inlet condition for soil and water while the interior and outflow boundary conditions were employed as mixture phase. During this process, the flow analysis considering the mixture was modeled in 2D. The numerical results are represented as contours and vectors for the soil-water discharges cases. As mentioned above, the 2D interior and outlet soil-water velocities were calculated from the 3D experimental area.

This study used the volume-of-fluid (VOF) method to analyze the behavior of multiphase fluids dealing with the pressurized pipe flow. For the calculation of turbulent flow, turbulence models such as the $k-\varepsilon$ model and the large eddy simulation (LES) model were used to calculate water level and flow velocity for each fluid volume of a finite-volume network of water bodies such as ports, estuaries, rivers, or sewers, by simulating both steady and unsteady flow conditions [41].

The Eulerian-Eulerian method obtains a flow rate field and a soil particle distribution field by solving the continuity Equations (1) and (2), the momentum Equations (3) the standard $k-\varepsilon$ turbulence equation. A conservative equation was derived at each step of this processing by combining all phases. Interphase bond was achieved through pressure and momentum exchange coefficients between the phases. Therefore, even in two-phase conditions, the sum of the volume concentrations must 
preserve a constant value of one. A two-phase fluid model with two continuous phases is governed by the Equations:

$$
\begin{gathered}
\frac{\partial \rho}{\partial t}+\frac{\partial\left(\rho u_{i}\right)}{\partial x_{i}}=\frac{\partial \rho}{\partial t}+\nabla \times(\rho \bar{u})=0 \\
\nabla \times(\rho \bar{u})=0 \\
\frac{\partial\left(\rho u_{i}\right)}{\partial t}+\frac{\partial\left(\rho u_{j} u_{i}\right)}{\partial x_{j}}=\frac{\partial \tau_{i j}}{\partial x_{j}}-\frac{\partial p}{\partial x_{i}}+F_{i}
\end{gathered}
$$

where $x_{i}(i=1,2,3)$ represents the orthogonal coordinates, $u_{i}$ the orthogonal (directional) element of the velocity vector that represents average flow velocity, $\rho$ is fluid density, $p$ is pressure, and $F_{i}$ is the sum of influential forces, such as gravity, deflecting force, and centrifugal force. For each dispersed phase to be expressed as a continuum, a high-volume concentration is required. The method lends itself well to flow analysis of phases with high density or concentration [42-45].

In Equation (4), $\tau_{i j}$ represents a viscous stress tensor representing Newtonian flow fluid, including the velocity of the deformed stress tensor; and $i j$ represents structural correlation [46-48]:

$$
\tau_{i j}=\left(\mu+\mu_{t}\right)\left(\frac{\partial u_{i}}{\partial x_{i}}+\frac{\partial u_{j}}{\partial x_{i}}\right)
$$

The $k-\varepsilon$ turbulence model, which we selected for the purpose of this study, is based on the Boussinesq assumption that the Reynolds stress generated during time integration of Navier-Stokes equations is proportional to the gradient of the mean flow rate. This assumption takes into account the eddy viscosity coefficient $\left(\mathrm{u}_{\mathrm{T}}\right)$ in Equations (5)-(7):

$$
\begin{gathered}
\mathrm{u}_{\mathrm{T}}=\rho \mathrm{C}_{\mathrm{u}} \frac{\mathrm{k}^{2}}{\varepsilon} \\
\frac{\partial}{\partial \mathrm{t}}(\rho \mathrm{k})+\frac{\partial}{\partial \mathrm{x}_{\mathrm{i}}}\left(\rho \mathrm{u}_{\mathrm{i}} \mathrm{k}\right)=\frac{\partial}{\partial \mathrm{x}_{\mathrm{i}}}\left(\frac{\mu_{\mathrm{T}}}{\sigma_{\mathrm{k}}} \frac{\partial \mathrm{k}}{\partial \mathrm{x}_{\mathrm{i}}}\right)+\mathrm{G}_{\mathrm{k}}+\mathrm{G}_{\mathrm{b}}+\rho \varepsilon \\
\frac{\partial}{\partial \mathrm{t}}(\rho \varepsilon)+\frac{\partial}{\partial \mathrm{x}_{\mathrm{i}}}\left(\rho \mathrm{u}_{\mathrm{i}} \varepsilon\right)=\frac{\partial}{\partial \mathrm{x}_{\mathrm{i}}}\left(\frac{\mu_{\mathrm{T}}}{\sigma_{\mathrm{k}}} \frac{\partial \varepsilon}{\partial \mathrm{x}_{\mathrm{i}}}\right)+\mathrm{C}_{1 \varepsilon} \frac{\varepsilon}{\mathrm{k}}\left(\mathrm{G}_{\mathrm{k}}+\left(1-\mathrm{C}_{3 \varepsilon}\right) \mathrm{G}_{\mathrm{b}}\right)-\mathrm{C}_{2 \varepsilon} \rho \frac{\varepsilon^{2}}{\mathrm{k}}
\end{gathered}
$$

where $\mathrm{C}_{\mathrm{u}}$ corresponds to the empirical constant, and $k$ and $\varepsilon$ are the turbulent kinetic energy and dissipation rate. Respectively. These can be calculated and using the transport Equations (5)-(7), where $C_{u}, \sigma_{k}, \sigma_{\varepsilon}, C_{1 \varepsilon}, C_{2 \varepsilon}$, and $C_{3 \varepsilon}$ are empirical constants $[41,49]$.

\subsection{Analysis Model Validation}

For 3D model analysis, configuration of the specifications of the sewer system to be analyzed should be preceded by the validation of the model to be developed, tailored to the analysis target. This is because validation with only the original model is insufficient, since it makes correcting of errors in case of upscaling labor-intensive and time-consuming. In this study, we validated a model constructed on the basis of earlier research in order to run a downscaled experimental model and reflect on the results when errors were detected.

We used the specifications determined in an experimental study with soil slurry particles measuring 1.4 to $2.0 \mathrm{~mm}$ by Matousek [50] to compare with the results of our numerical analysis. We validated our model by applying the same diameter, density, and composition ratio of water and soil particles of the soil slurry, and the specifications and gradients of the sewer system as that earlier study. Regarding particle-size distribution, our analysis was performed by injecting the same quantity of soil particles sized 1.4, 1.53, 1.68, 1.84, and $2.0 \mathrm{~mm}$. For verification, we identified the concentration profiles conforming to those obtained experimentally from measurements at the deposition sites in each section 
of the sewer system. We then checked the time of sediment deposition over the entire section of the sewer system, and identified the sediment distribution pattern.

Song et al. [32] also compared the results of numerical analysis of their study in a sewer system with these earlier experimental results [50], using the same flow conditions (volume concentration: 26\%; flow velocity: $2.5-3.0 \mathrm{~m} / \mathrm{s}$ ), with soil particles sized 1.4-2.0 $\mathrm{mm}$. The results of this comparison are presented in Figure 1. Extending this experiment, the present study added a flow velocity condition of $3.5 \mathrm{~m} / \mathrm{s}$ (Figure 2). The patterns of our modeling results are generally in good agreement with the experimental results. The turbulence model for our numerical analysis was validated by the observation that the volume concentration-dependent internal distribution profiles showed the same tendency in both flow velocity conditions.

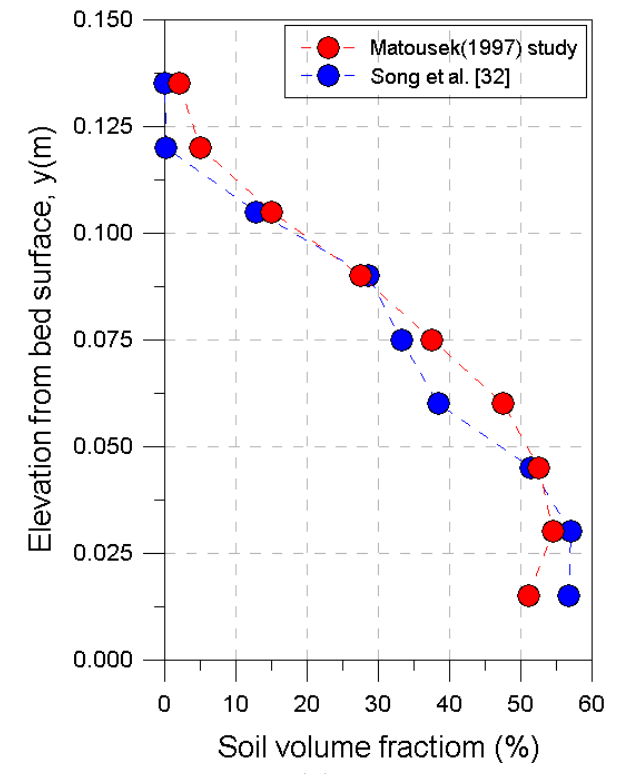

(a)

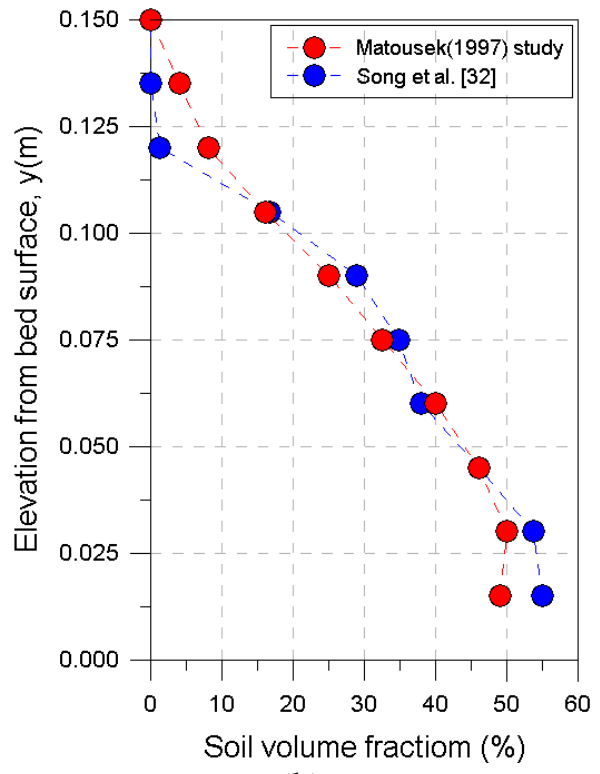

(b)

Figure 1. Comparison of modeling results by Song et al. [32], with earlier experimental data [50]. (a) flow velocity: $2.5 \mathrm{~m} / \mathrm{s}$; (b) flow velocity: $3.0 \mathrm{~m} / \mathrm{s}$.

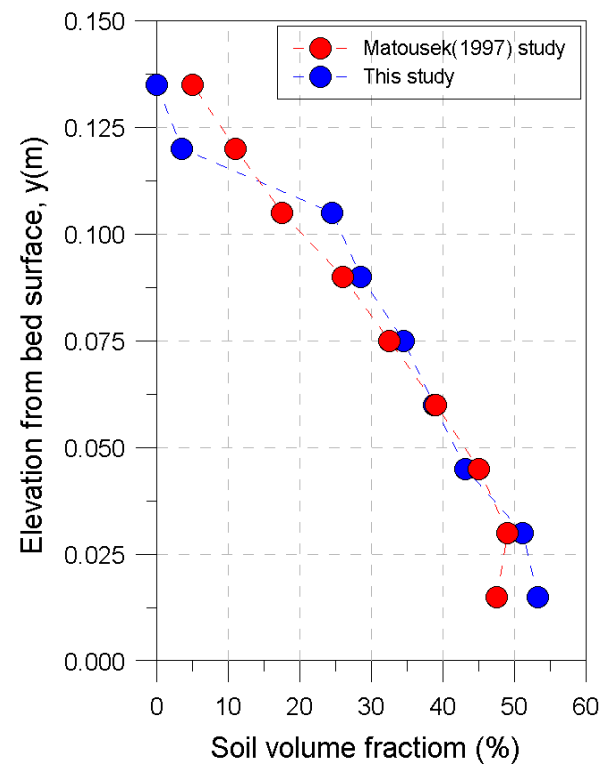

Figure 2. Comparison of modeling verification results (this study) with experimental data [50], for flow velocity of $3.5 \mathrm{~m} / \mathrm{s}$. 


\subsection{Numerical Analysis Conditions}

The characteristics, and transport and deposition processes of sediments inside stormwater pipes, are distinct from those of sediments on riverbeds. Sediments on the riverbed contain sand and gravel particles of different sizes. Sediments flowing into a stormwater sewer through a manhole, by contrast, contain a limited range of particle sizes, and consequently show no significant variance in density and unit weight values. Sediments in a sewer system thus have more uniform characteristics compared with those on the riverbed.

As illustrated in Figure 3, we simulated the soil slurry transport and sedimentation processes by configuring a stormwater sewer measuring $0.6 \mathrm{~m}$ by $10 \mathrm{~m}$ and consisting of 140,000 grid meshes; the Cartesian coordinate system under pipe flow was governed by the control equation. We conducted a 2D-model analysis, which had a high computation efficiency under the same inlet conditions. Using the inlet velocity of soil slurry and volume concentration and particle size of the soil as variables, we compared and analyzed the flow velocity and particle distribution profiles of the slurry mixtures in a total of 63 conditions. The calculation was performed up to a total of $500 \mathrm{~s}$ by applying the calculation time interval $\Delta t=1 \mathrm{~s}$, and the calculation was set to repeat 10 times the internal calculation (step length factor). Using very small values in repetitions of the computation could have led to a termination of the analysis during particle transport and deposition, the intervals used in the study reflected sufficiently leisurely to avoid this result. It was confirmed that the results did not change during the course of the analysis and that a constant value was derived. Table 1 presents the material properties of the input mixture of fluid and soil slurry and the boundary conditions of our numerical analysis.

Table 1. Input and boundary conditions for the numerical analysis in this study.

\begin{tabular}{cc}
\hline Classification & Fluid-Soil Interaction Modelling in Pipe \\
\hline Pipe specification & $0.6 \mathrm{~m}(\mathrm{D}) \times 10 \mathrm{~m}(\mathrm{~L})$ \\
Mesh specification & Generate 140,000 grid \\
& Euler-Euler Model \\
Applied models and flow condition & Standard $k$ - $\varepsilon$ model \\
& Turbulent flow \\
Pipe inlet condition & Inlet velocity condition $(\mathrm{m} / \mathrm{s}): 1.0,2.0,3.0$ \\
Fluid property & Inlet volume fraction condition $(\%): 10,30,50$ \\
Soil slurry property & Density $\left(\mathrm{kg} / \mathrm{m}^{3}\right): 998.2$ \\
& Kinematic viscosity: $0.001003 \mathrm{~Pa} \cdot \mathrm{s}$ \\
& Density $\left(\mathrm{kg} / \mathrm{m}^{3}\right): 2650$ \\
\end{tabular}

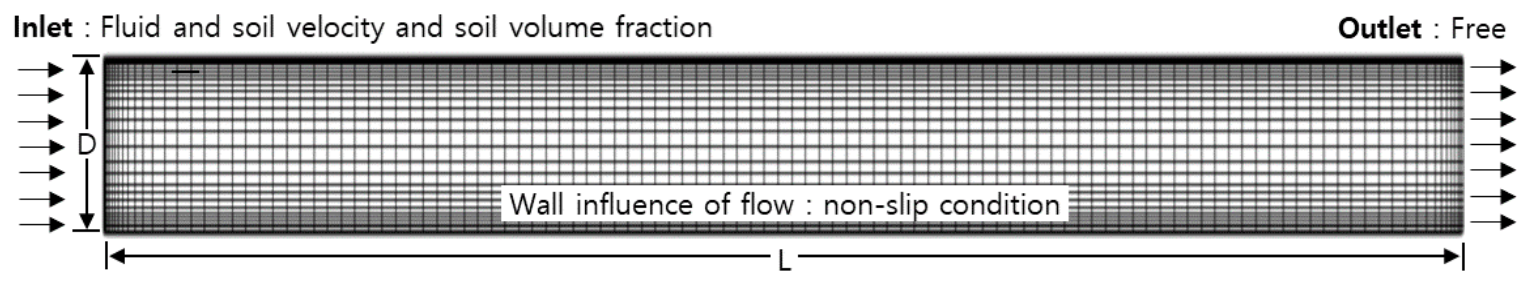

Figure 3. Mesh of a stormwater pipe and boundary conditions applied in this study [31,32].

\section{Results}

\subsection{Flow Characteristics of a Soil Slurry Mixture in the Stormwater Sewer System}

For analysis of multiphase flows including fluid-soil phases, the total pressure drop in the pipe is basically related to four main components: frictional, hydrostatic, acceleration, and pressure drop. In many applications, the calculation of the pressure drop is the most complex component. The deposition of a sediment layer on the bottom of the pipe is a major cause of formation of a shear boundary layer in the soil slurry transport process, and thus serves as a major reference point for 
facility maintenance. Friction velocity is a key parameter used in studies of erosion in waterbodies (streams, estuaries, etc.) and airborne particle transport. Friction velocity, defined as the square root of the ratio between wall shear stress over fluid density; it is decided by near wall flow conditions. Boundary layers are classified according to the relative value of shear velocity, and a sediment layer is formed by particles having a shear force exceeding that value. A major factor influencing the process of soil slurry transport and deposition is flow resistance. Sediments settle on the bottom of the pipe and thus increase the flow resistance and decrease the area of discharge, as shown in Figure 4.

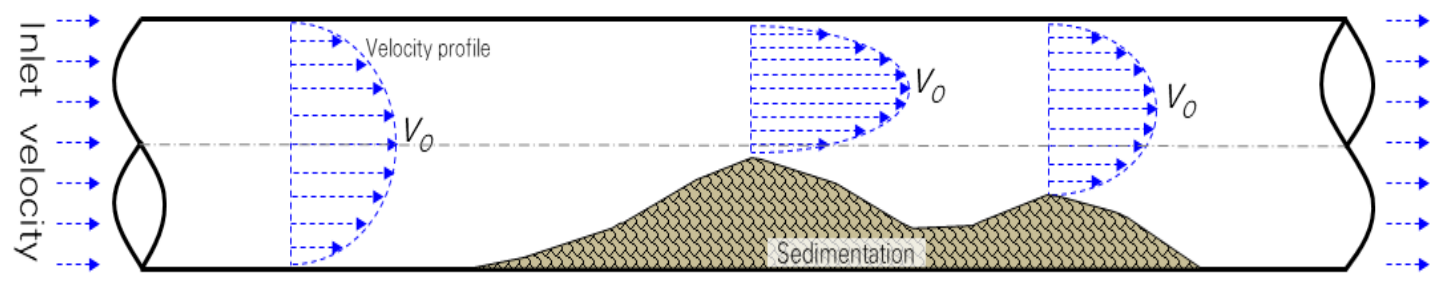

Figure 4. Change of the velocity profile of turbulent flow within a pipe due to sedimentation.

Earlier works have noted that the migration of sediments in a stormwater sewer occurs in three basic stages: entrainment, transport, and deposition [51,52]. Figure 5 presents the shear characteristics for each stage. The thickness of boundary layers is not uniform, and most of the flow segments are zones of turbulent flow.

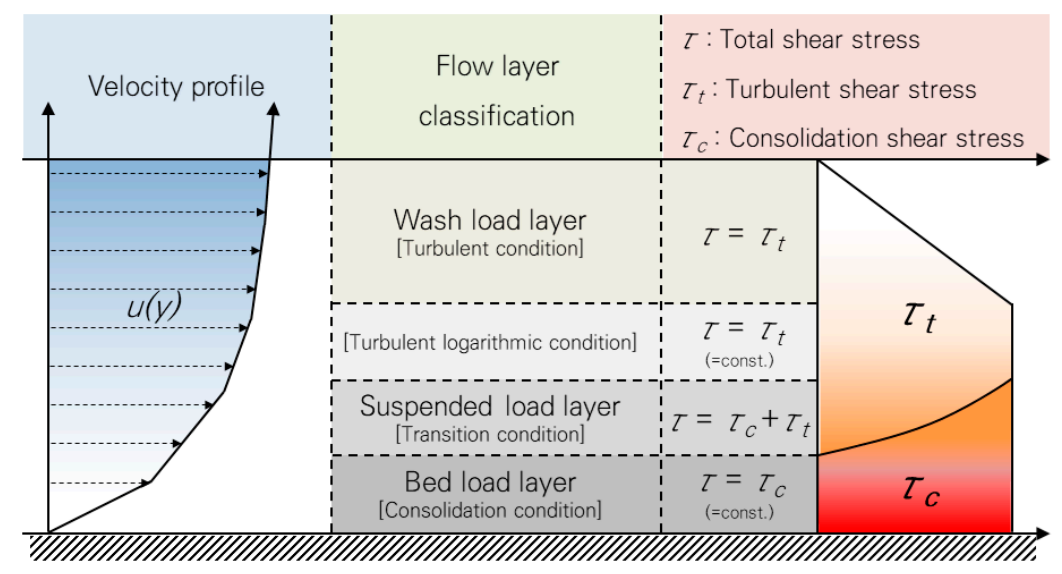

Figure 5. Classification of the flow layer according to shear stress characteristics.

The demarcation of the boundary layers is determined by the relative magnitudes of shear velocity $\left(u_{*}\right)$ and settling velocity $\left(v_{s}\right)$ of particles on the pipe bottom [53], as shown in Figure 4.

Putting Figure 5 and Table 2 in context, different layers can be defined in the context of slurry transport and sedimentation: the term "bedload layer" refers to a layer on which interparticle adhesion force acts as a force to keep the particles together on the bottom (bed) of the pipe, making them migrate together; the term "transition layer" refers to a boundary layer atop an existing sediment layer, on which deposited particles are separated from the sediment layer under high turbulence stress and move along with the flow; and the "wash load layer" and "suspended load layer" are subjected only to turbulence stress during transport.

Table 2. Flow conditions and sediment transport status [53].

\begin{tabular}{cc}
\hline Condition & Sediment Transport Status \\
\hline $\mathrm{v}_{\mathrm{S}} / \mathrm{u}_{*}<0.6$ & - Particle travel in suspension \\
$0.6<\mathrm{v}_{\mathrm{S}} / \mathrm{u}_{*}<2.0$ & - Particle travel in saltation \\
$\mathrm{v}_{\mathrm{S}} / \mathrm{u}_{*}>2.0$ & - Particle travel as bedload \\
\hline
\end{tabular}


Since the frictional resistance to the flow is minimal, the particles contained in soil slurry have a very low settling velocity. Therefore, turbulence stress exists as a complete turbulent flow. Based on the flow direction of the sewer pipe, shear stress decreases linearly towards the upper end, where flow velocity becomes 0 and intense mixing between fluid and solid particles occurs. Despite the presence of vortices or eddies, such sections are characterized by steady flow velocity. As discussed above, several flow boundary layers emerge in the process of soil slurry transport, but it needs to be pointed out that clear demarcation between these flow systems is impossible.

Shear stress on the bottom of the pipe are the forces that carry and transport sediments. The important ratio in the mechanics of the shear boundary layer is the flow on the bed per unit area. The threshold value (critical boundary shear stress or critical erosion rate) is the value of the shear stress (threshold of motion) below which no entrainment can take place. Bottom (or bed) roughness is determined by the size of sediment particles accumulated on the bottom; it affects the flow rate distribution and sediment transport capacity in the pipe.

In summary, settling velocity affects sediment transport by exerting hydrodynamic force on the sediment particles, and thus causing the formation of boundary layers. With increase in the flow velocity in turbulent flow conditions, the force acting on the sediment particles exceeds the threshold value, and particles deposited on the bottom of the pipe reach the level of re-entrainment at a constant speed. This suggests that, in the critical condition, shear stress in the pipe dominates the sediment flow, showing high dependence on flow velocity.

\subsection{Analysis of the Flow Boundary Layer in Stormwater Pipes}

In the case of rivers, analysis of discharge capacity can be based on various observations. This enables estimation of the influence of hydraulic parameters. Most of the previous studies of sedimentation have focused on riverbed data, and settling velocity has been used only as a concept associated with sediment transport. In the case of stormwater drainage, however, it is unlikely that the characteristics of the inlet soil slurry, that determine settling velocity, remain constant. It is reasonable to assume the value of each of these characteristic varies. Likewise, the application of a uniform settling velocity is unlikely to properly reflect the phenomenon of sediment transport in a stormwater sewer system.

The main characteristics that determine the boundary layer during the flow of turbid water in sewer pipes are the vertical distribution and the boundary layer of shear velocity on the bottom of the pipe. In this context, by investigating the shear velocity due to the sediment layer, we can measure the change in the shear velocity on the bottom of the pipe. Shear flow velocity and shear stress at the bottom represent the force accompanying and transferring the deposits. The shear stress along the critical boundary or the critical erosion speed is the limiting condition of deposit transfer and shear stress (limiting point of motion) at the start of the yield. The value of roughness at the bottom depends on the size of sediment particles there, and influences changes in the flow velocity distribution and the transfer capability of the soil slurry [17,27,32]. The shear flow velocity (also known as the friction velocity or shear-stress velocity), $\mathrm{u}_{*}$, of a flow is defined by the relation Equation (8), where $\tau$ is the shear stress in an arbitrary layer of fluid and $\rho$ is the density of the fluid. This quantity has the dimensions of velocity and is frequently encountered in the study of boundary layers. For turbulent flow it is approximately constant in the region near to a wall. The flow velocity in the boundary layer is commonly expressed in terms of the friction velocity and the height, $\mathrm{z}$

$$
u_{*}=\sqrt{\tau / \rho}
$$

When the flow velocity distribution on a given cross-section is known, shear velocity can be estimated using Equation (9), based on the Law of the Wall, widely used for a relatively thin layer $(\mathrm{z} / \mathrm{H}<0.2)$ close to the bottom:

$$
\frac{\mathrm{u}}{\mathrm{u}_{*}}=\frac{1}{\mathrm{~K}} \ln \left(\frac{\mathrm{z}}{\mathrm{z}_{\mathrm{o}}}\right)
$$


where $\mathrm{u}$ is the mean flow velocity at the upper distance $\mathrm{z}$ relative to the bottom, $\mathrm{z}_{0}$ is the distance from the bottom where flow velocity tends to $0, \mathrm{u}_{*}$ is the shear velocity, and $\kappa$ is von Karman's constant $(\sim 0.41)[54,55]$.

Accordingly, the shear velocity and shear stress during transport and deposition can be calculated by considering the change caused by the continuous increase in velocity occurring on the boundary layer on the bottom of the pipe. The shear force is the frictional resistance generated along the pipe wall during flow. Therefore, by applying the change owing to an increase in continuous velocity occurring along the boundary of the bottom of the conduit, the shear flow velocity and shear stress in transfer deposition can be calculated. If $\mathrm{y}$ increases discontinuously at a certain calculation point, $\partial \mathrm{u} / \partial \mathrm{z}$ in Equation (10) increases infinitely [56-61]. This frictional resistance is proportional to the flow velocity and inversely proportional to the cross-sectional area of the pipe. The shearing stress operating on the pipe plane at height $\mathrm{z}$ in a flow depth $\mathrm{h}$ and $\theta$ in the channel slope is given. Expressed as the shear rate or shear stress, $\tau$, it can be calculated from Equation (10) in Newtonian fluid [49,58]:

$$
\tau=\mu \frac{\partial u}{\partial z}=\rho g \sin \theta(h-z)
$$

where $\mu$ is the dynamic viscosity of the fluid. If y increases discontinuously at a given calculation point, however, $\partial \mathrm{u} / \partial \mathrm{z}$ in Equation (10) increases ad infinitum. The shear stress at the point where the change in flow velocity tapers off can be defined as the limiting shear stress.

Figure 6 shows the results of numerical analysis of soil slurry with $0.5 \mathrm{~mm}$ particle size. Figure 7 below illustrates the shear velocity distribution profiles during the transport and deposition of soil slurry with particle diameter of $0.5 \mathrm{~mm}$. It shows that the change in shear velocity has converged values on the bottom of the pipe, and that shear velocity does not change beyond a certain distance from the wall, demonstrating that shear friction exerts a greater force on the bottom, but does not extend to the pipe center.

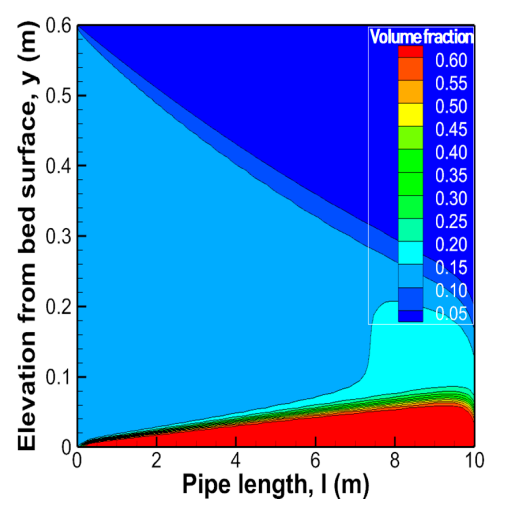

(a)

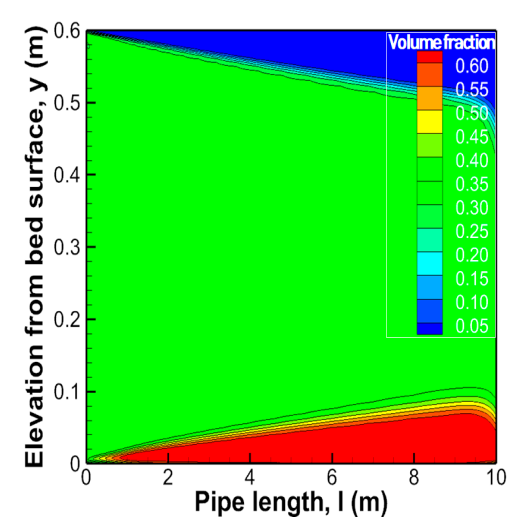

(b)

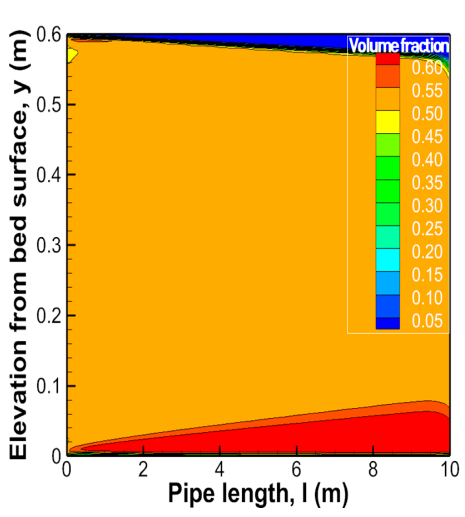

(c)

Figure 6. Representative results of numerical modelling of for soil slurry of $0.5 \mathrm{~mm}$ particle diameter; (a) $1.0 \mathrm{~m} / \mathrm{s}, 10 \% \mathrm{v} / \mathrm{f}$ condition; (b) $2.0 \mathrm{~m} / \mathrm{s}, 30 \% \mathrm{v} / \mathrm{f}$ condition; (c) $3.0 \mathrm{~m} / \mathrm{s}, 50 \% \mathrm{v} / \mathrm{f}$ condition.

The settling velocity of sediment particles, also called the terminal or fall velocity, is one of the key variables in the study of sediment transport and is important in understanding suspension, deposition, mixing and exchange processes. Based on the results of numerical analysis, we used Equation (11) to calculate the settling velocity $\left(\mathrm{v}_{\mathrm{s}}\right)$ in the thin layer on the bottom of the pipe [62]:

$$
\mathrm{v}_{\mathrm{s}}=\sqrt{\left(\frac{\rho_{\mathrm{s}}-\rho}{\rho}\right)^{1 / 3}\left(\frac{\mathrm{gd} \mathrm{d}_{\mathrm{p}}}{C_{\mathrm{D}}}\right)}
$$

where $\left(\rho_{\mathrm{s}}-\rho\right) / \rho$ is the specific gravity (submerged) of the sediment in the fluid, $\rho_{\mathrm{s}}$ is the density of the sediment $\left(\mathrm{kg} / \mathrm{m}^{3}\right), \rho$ is the density of water $\left(\mathrm{kg} / \mathrm{m}^{3}\right), \mathrm{g}$ is the gravitational acceleration $\left(\mathrm{m} / \mathrm{s}^{2}\right), \mathrm{d}_{\mathrm{p}}$ is 
the particle diameter $(\mathrm{mm})$, and $\mathrm{C}_{\mathrm{D}}$ is the coefficient of drag. The coefficient of drag varies depending on the degree of freedom of motion of the particles; however, given that its value usually converges to 0.44 in a turbulent flow, the latter value was used for this calculation. Table 3 presents the input settling velocity by particle size at $\left(\mathrm{g} \mathrm{d}_{\mathrm{p}} / \mathrm{C}_{\mathrm{D}}\right)$ as calculated from Equation (10). Table 4 shows the shear velocity values calculated from two-phase analysis. Table 5 presents the results from the analysis of the shear boundary layer under all 63 conditions of shear velocity, as listed in Table 4 .

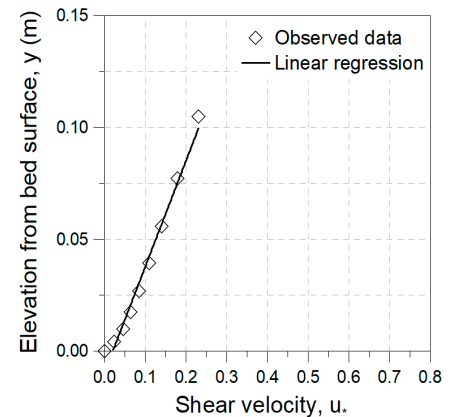

(a)

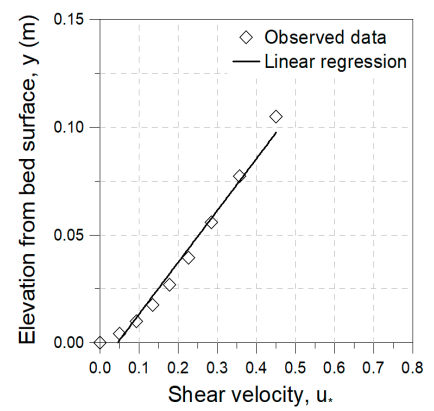

(b)

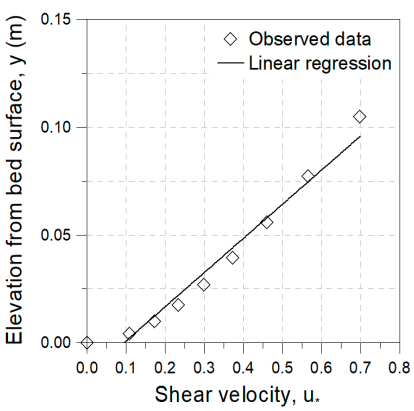

(c)

Figure 7. Representative distribution of shear velocity for soil slurry of $0.5 \mathrm{~mm}$ particle diameter; (a) $1.0 \mathrm{~m} / \mathrm{s}, 10 \% \mathrm{v} / \mathrm{f}$ condition; (b) $2.0 \mathrm{~m} / \mathrm{s}, 30 \% \mathrm{v} / \mathrm{f}$ condition; (c) $3.0 \mathrm{~m} / \mathrm{s}, 50 \% \mathrm{v} / \mathrm{f}$ condition.

Table 3. Settling velocity by particle size.

\begin{tabular}{ccc}
\hline Soil Diameter $\left(\mathbf{d}_{\boldsymbol{p}}\right), \mathbf{m m}$ & $\mathbf{g} \mathbf{d}_{\mathbf{p}} / \mathbf{C}_{\mathbf{D}}$ & Settling Velocity $\left(\mathbf{v}_{\mathbf{s}}\right)$ \\
\hline 0.5 & 0.0111 & 0.1148 \\
1.0 & 0.0223 & 0.1623 \\
3.0 & 0.0669 & 0.2811 \\
5.0 & 0.1115 & 0.3629 \\
7.0 & 0.1561 & 0.4294 \\
15.0 & 0.3344 & 0.6286 \\
20.0 & 0.4459 & 0.7259 \\
\hline
\end{tabular}

Table 4. Shear velocity results from two-phase flow analysis.

\begin{tabular}{|c|c|c|c|c|c|c|c|c|c|}
\hline \multirow{3}{*}{$\mathrm{d}_{p}(\mathrm{~mm})$} & \multicolumn{9}{|c|}{$\mathbf{u} *$ (Shear Velocity) } \\
\hline & \multicolumn{3}{|c|}{$1.0 \mathrm{~m} / \mathrm{s}$} & \multicolumn{3}{|c|}{$2.0 \mathrm{~m} / \mathrm{s}$} & \multicolumn{3}{|c|}{$3.0 \mathrm{~m} / \mathrm{s}$} \\
\hline & $10 \% \mathrm{v} / \mathrm{f}$ & $30 \% \mathrm{v} / \mathrm{f}$ & $50 \% \mathrm{v} / \mathrm{f}$ & $10 \% \mathrm{v} / \mathrm{f}$ & $30 \% \mathrm{v} / \mathrm{f}$ & $50 \% \mathrm{v} / \mathrm{f}$ & $10 \% \mathrm{v} / \mathrm{f}$ & $30 \% \mathrm{v} / \mathrm{f}$ & $50 \% \mathrm{v} / \mathrm{f}$ \\
\hline 0.5 & 0.016 & 0.022 & 0.021 & 0.017 & 0.018 & 0.018 & 0.048 & 0.050 & 0.050 \\
\hline 1.0 & 0.024 & 0.024 & 0.022 & 0.035 & 0.109 & 0.033 & 0.060 & 0.065 & 0.063 \\
\hline 3.0 & 0.054 & 0.042 & 0.045 & 0.040 & 0.038 & 0.037 & 0.065 & 0.069 & 0.070 \\
\hline 5.0 & 0.061 & 0.064 & 0.067 & 0.067 & 0.051 & 0.067 & 0.047 & 0.054 & 0.053 \\
\hline 7.0 & 0.073 & 0.073 & 0.064 & 0.071 & 0.073 & 0.068 & 0.063 & 0.079 & 0.080 \\
\hline 15.0 & 0.112 & 0.112 & 0.121 & 0.096 & 0.105 & 0.108 & 0.101 & 0.101 & 0.111 \\
\hline 20.0 & 0.125 & 0.139 & 0.132 & 0.131 & 0.125 & 0.129 & 0.126 & 0.133 & 0.135 \\
\hline
\end{tabular}


Table 5. Shear boundary layer in various conditions of sediment load and settling velocity. Settling velocity was calculated from numerical analysis results $\left(v_{s} / u_{*}\right)$.

\begin{tabular}{|c|c|c|c|c|c|c|c|c|c|c|}
\hline \multirow{2}{*}{\multicolumn{2}{|c|}{ Velocity $v / f d_{p}$ Load }} & \multicolumn{3}{|c|}{$1.0 \mathrm{~m} / \mathrm{s}$ Condition } & \multicolumn{3}{|c|}{$2.0 \mathrm{~m} / \mathrm{s}$ Condition } & \multicolumn{3}{|c|}{$3.0 \mathrm{~m} / \mathrm{s}$ Condition } \\
\hline & & $10 \%$ & $30 \%$ & $50 \%$ & $10 \%$ & $30 \%$ & $50 \%$ & $10 \%$ & $30 \%$ & $50 \%$ \\
\hline \multirow{3}{*}{$\begin{array}{c}0.5 \\
\mathrm{~mm}\end{array}$} & Bed & 1.141 & 1.321 & 1.227 & 0.916 & 0.857 & 0.841 & 0.809 & 0.767 & 0.761 \\
\hline & Suspended & 0.120 & 0.106 & 0.109 & 0.154 & 0.154 & 0.169 & 0.193 & 0.205 & 0.203 \\
\hline & Wash & 0.048 & 0.047 & 0.044 & 0.043 & 0.043 & 0.044 & 0.042 & 0.042 & 0.042 \\
\hline \multirow{3}{*}{$\begin{array}{c}1.0 \\
\mathrm{~mm}\end{array}$} & Bed & 1.219 & 1.219 & 1.171 & 1.023 & 1.029 & 1.034 & 0.906 & 0.872 & 0.879 \\
\hline & Suspended & 0.122 & 0.122 & 0.115 & 0.100 & 0.098 & 0.099 & 0.184 & 0.185 & 0.186 \\
\hline & Wash & 0.049 & 0.049 & 0.053 & 0.046 & 0.049 & 0.044 & 0.047 & 0.042 & 0.042 \\
\hline \multirow{3}{*}{$\begin{array}{c}3.0 \\
\mathrm{~mm}\end{array}$} & Bed & 1.272 & 1.314 & 1.277 & 1.054 & 1.073 & 1.072 & 1.004 & 1.049 & 1.035 \\
\hline & Suspended & 0.137 & 0.149 & 0.164 & 0.121 & 0.118 & 0.117 & 0.101 & 0.100 & 0.101 \\
\hline & Wash & 0.043 & 0.043 & 0.040 & 0.046 & 0.046 & 0.050 & 0.046 & 0.046 & 0.046 \\
\hline \multirow{3}{*}{$\begin{array}{l}5.0 \\
\mathrm{~mm}\end{array}$} & Bed & 1.199 & 1.055 & 1.202 & 0.985 & 0.978 & 0.894 & 0.907 & 1.086 & 0.988 \\
\hline & Suspended & 0.139 & 0.152 & 0.177 & 0.122 & 0.120 & 0.117 & 0.112 & 0.113 & 0.113 \\
\hline & Wash & 0.036 & 0.030 & 0.029 & 0.046 & 0.047 & 0.052 & 0.046 & 0.047 & 0.046 \\
\hline \multirow{3}{*}{$\begin{array}{l}7.0 \\
\mathrm{~mm}\end{array}$} & Bed & 0.776 & 1.274 & 1.192 & 1.048 & 0.978 & 0.904 & 0.865 & 1.021 & 0.780 \\
\hline & Suspended & 0.114 & 0.127 & 0.126 & 0.115 & 0.127 & 0.125 & 0.116 & 0.119 & 0.115 \\
\hline & Wash & 0.032 & 0.032 & 0.032 & 0.042 & 0.043 & 0.042 & 0.048 & 0.045 & 0.049 \\
\hline \multirow{3}{*}{$\begin{array}{l}15.0 \\
\mathrm{~mm}\end{array}$} & Bed & 0.705 & 0.617 & 0.614 & 0.682 & 0.688 & 0.664 & 0.650 & 0.704 & 0.731 \\
\hline & Suspended & 0.109 & 0.118 & 0.116 & 0.121 & 0.129 & 0.130 & 0.117 & 0.118 & 0.127 \\
\hline & Wash & 0.026 & 0.033 & 0.032 & 0.038 & 0.042 & 0.042 & 0.043 & 0.044 & 0.044 \\
\hline \multirow{3}{*}{$\begin{array}{l}20.0 \\
\mathrm{~mm}\end{array}$} & Bed & 0.662 & 0.603 & 0.616 & 0.479 & 0.520 & 0.487 & 0.592 & 0.578 & 0.609 \\
\hline & Suspended & 0.115 & 0.105 & 0.110 & 0.122 & 0.121 & 0.141 & 0.115 & 0.111 & 0.121 \\
\hline & Wash & 0.023 & 0.033 & 0.036 & 0.039 & 0.039 & 0.047 & 0.042 & 0.047 & 0.047 \\
\hline
\end{tabular}

\section{Discussion}

Looking at these results (Table 5), most of the sediments exceeding the value of 2.0 were not transported, but were deposited on the bottom, as has also been reported in earlier works [53]. In our study, however, at the mean value less than 1.0 also tended to be deposited in the stormwater sewer system. From the abrupt increase in shear velocity $(0.2-0.9 \mathrm{~m} / \mathrm{s})$, it can be inferred that the corresponding boundary layer is one of alternately recurring transport and deposition due to particle saltation, with a proportion of sediments traveling in suspended load. Sediment particles with a settling velocity value less than $0.2 \mathrm{~m} / \mathrm{s}$ were subjected to frequent changes in shear velocity, resulting in turbid flow in suspended load. Table 6 provides mathematical formulas for the shear velocity conditions of the turbulent boundary layer with respective sediment transport/deposition status. Our work thus verified that shear velocity $\left(u_{*}\right)$ and settling velocity $\left(v_{s}\right)$ can be used to easily distinguish between the transport or deposition status of particles with respect to the flow characteristics of soil slurry in stormwater pipes. Adhesion and consolidation may be defined as the process by which the sediment density increased. Sediments change their physical properties after deposition due to the stress from the overburden (gravitational compaction) and as a result of settling reactions involving coagulation. It should be noted that if the initial sediment concentration exceeds a certain value, there will be no initial free settlement stage, and the sediment settlement directly enters the hindered settlement or self-weight consolidation settlement stage $[59,63]$. This allows the prediction of the boundary layer for each particle transport status. 
Table 6. Classification of turbulent boundary layer (this study).

\begin{tabular}{cc}
\hline Condition & Sediment Transport Status \\
\hline $\mathrm{v}_{\mathrm{S}} / \mathrm{u}_{*}<0.04$ & - Particles travel in wash load. \\
$0.04<\mathrm{v}_{\mathrm{S}} / \mathrm{u}_{*}<0.13$ & - Particles travel in suspension. \\
$0.13<\mathrm{v}_{\mathrm{S}} / \mathrm{u}_{*}<0.91$ & - Partial transport on the pipe bed or sediment boundary layer. \\
$\mathrm{v}_{\mathrm{S}} / \mathrm{u}_{*}>0.91$ & - Particles travel as bed load. \\
\hline
\end{tabular}

The results presented in this paper are estimations derived from the numerical analysis of various inlet conditions of soil slurry entering the stormwater sewer system. Analysis of the settling velocity, with the particle size used as a major parameter, permitted the quantification of the sediment transport status in sediment layers within sewer pipes. The key advantage of the boundary layer investigation approach described in this study is that it can predict the thickness of the boundary layer for transport of soil slurry in both low-volume concentration conditions, and, also, in high-volume concentration conditions, involving transport of large quantities of soil slurry. Furthermore, unlike earlier numerical models of riverbeds, results from this study are applicable to stormwater sewers.

The parameters selected in this study to investigate the shear boundary layer fall within the range of the parameters proposed by earlier workers [53]. This confirms that the method proposed in this study produces reliable results. However, this study is limited by the fact that it is based on the single scenario that a large quantity of soil slurry enters the sewer system in the initial hours of a rainfall event.

This study is expected to serve as the basis for designing drainage pipelines and for mitigating clogging or destruction of drainage pipelines due to disasters (e.g., landslides) caused by localized torrential rainfall. However, prior to examining sewer flow patterns for various types of soil particles and floating debris that enter the drainage channel, it is necessary to analyze various conditions by integrating numerical analyses into hydraulic model experiments. Validation of the proposed methodology through its application to many different rainfall event scenarios and through comparison with direct observations in in actual sewer systems are, therefore, required.

\section{Conclusions}

In this study, we investigated turbulent flow in stormwater pipes, and performed numerical analysis to determine the effects of soil slurry transport and deposition. A turbulence model was developed, and shear velocity was calculated using flow velocity and sediment volume concentration as parameters. Based on the analysis results, we developed a new approach to identify the turbulent shear boundary layer related to soil slurry transport in stormwater pipes. We conducted numerical analysis to understand the turbulent flow in sewer pipes where transport and deposition take place, and analyzed the effects of soil slurry transport and deposition. Applying a turbulence model, we investigated the mean flow velocity, volume distribution, shear velocity, and shear stress. The following conclusions were drawn from this analysis:

(1) In conditions of slow inlet velocity of slurry particles and large particle diameter, the soil slurry traveled in suspended load closer to the bottom; in conditions of high inlet velocity and smaller particle diameter, the soil slurry flow showed a higher suspended load transport.

(2) When slurry solids are deposited near the inlet, the flow on the sediment boundary layer is accelerated, resulting in entrainment and transport of slurry particles. When slurry enters the inlet slowly and particle diameter is large, deposition of a larger quantity of solids impedes slurry transport.

(3) The overall flow rate distribution was weakened due to the drag caused by the similar volume fraction in the sewer channel with sedimentation characteristics, and the flow velocity gradient in the pipe increased due to sedimentation. 
Based on the analysis of the flow velocity field in the pipe, the boundary layers were expressed as the relationship between shear velocity and settling velocity by particle diameter. Since the mean flow velocity and volume concentration in the pipe under different conditions exhibited similar patterns, we averaged the correlation between settling velocity and shear velocity. It is clear that there are no quantitative results in the literature on the standard high Reynolds number $k-\varepsilon$ model of turbulent pipe flow. The information given by Launder and Spalding [33] about this model is only qualitative. In order to compensate for these limitations, the turbulence intensity of the pipe core for the fully developed pipe flow was estimated through a sufficient review of various prior studies and reflected in the analysis. In order to fill this gap, in this paper we present accurate spectral solutions of this model. The results obtained are encouraging and tend to prove that the standard $k-\varepsilon$ model can be relevant for pipe flows.

It is expected that this research methodology can be improved and refined by checking the boundary layer model proposed here against the direct observations in actual stormwater pipes. This will be the subject of a follow-up study.

Author Contributions: Y.H.S.; J.G.J.; J.H.L. and D.G.Y. conceived the original idea and designed the research method; Y.H.S. and D.G.Y. reviewed the relevant literature and wrote the article; Y.H.S. and J.G.J. revised the article. All authors have read and agreed to the published version of the manuscript.

Funding: This research was supported by Basic Science Research Program through the National Research Foundation of Korea (NRF), funded by the Ministry of Education (NRF-2019R1A6A3A01092852).

Conflicts of Interest: The authors declare no conflict of interest.

\section{References}

1. Na, W.; Yoo, C. Optimize short-term rainfall forecast with combination of ensemble precipitation nowcasts by Lagrangian extrapolation. Water 2019, 111, 1752. [CrossRef]

2. Song, Y.; Park, Y.; Lee, J.; Park, M.; Song, Y. Flood forecasting and warning system structures: Procedure and application to a small urban stream in South Korea. Water 2019, 11, 1571. [CrossRef]

3. Lee, E.H. Advanced operating technique for centralized and decentralized reservoirs based on flood forecasting to increase system resilience in urban watersheds. Water 2019, 11, 1533. [CrossRef]

4. Najafzadeh, M.; Rezaie Balf, M.; Rashedi, E. Prediction of maximum scour depth around piers with debris accumulation using EPR, MT, and GEP models. J. Hydroinform. 2016, 18, 867-884. [CrossRef]

5. Panici, D.; de Almeida, G.A. A theoretical analysis of the fluid-solid interactions governing the removal of woody debris jams from cylindrical bridge piers. J. Fluid Mech. 2020, 886. [CrossRef]

6. Kang, C.; Chan, D. Modeling of entrainment in debris flow analysis for dry granular material. Int. J. Geomech. 2017, 17, 04017087. [CrossRef]

7. De Campos, T.M.P.; Galindo, M.S.V. Evaluation of the viscosity of tropical soils for debris flow analysis: A new approach. Géotechnique 2016, 66, 533-545. [CrossRef]

8. Kwan,J.S.; Sze, E.H.; Lam, C. Finite element analysis for rockfall and debris flow mitigation work. Can. Geotech. J. 2019, 56, 1225-1250. [CrossRef]

9. Xiong, K.; Adhikari, B.R.; Stamatopoulos, C.A.; Zhan, Y.; Wu, S.; Dong, Z.; Di, B. Comparison of different machine learning methods for debris flow susceptibility mapping: A case study in the Sichuan Province, China. Remote Sens. 2020, 12, 295. [CrossRef]

10. Regueiro-Picallo, M.; Suárez, J.; Sañudo, E.; Puertas, J.; Anta, J. New insights to study the accumulation and erosion processes of fine-grained organic sediments in combined sewer systems from a laboratory scale model. Sci. Total Environ. 2020, 716, 136923. [CrossRef]

11. Danandeh Mehr, A.; Safari, M.J.S. Application of soft computing techniques for particle Froude Number estimation in sewer Pipes. J. Pipeline Syst. Eng. Pract. 2020, 11, 04020002. [CrossRef]

12. Ebtehaj, I.; Bonakdari, H.; Safari, M.J.S.; Gharabaghi, B.; Zaji, A.H.; Madavar, H.R.; Khozani, Z.S.; Es-haghi, M.S.; Shoshegaran, A.; Mehr, A.D. Combination of sensitivity and uncertainty analyses for sediment transport modeling in sewer pipes. Int. J. Sediment. Res. 2020, 35, 157-170. [CrossRef]

13. Rinas, M.; Fricke, A.; Tränckner, J.; Frischmuth, K.; Koegst, T. Sediment transport in sewage pressure pipes, part II: 1D numerical simulation. Water 2020, 12, 282. [CrossRef] 
14. Zuo, Z.; Zheng, M.; Chang, J.; Ren, D.; Huang, X.; Yuan, Z.; Liu, Y. Free nitrous acid-based suppression of sulfide production in sewer sediments: In-situ effect mechanism. Sci. Total Environ. 2020, 715, 136871. [CrossRef] [PubMed]

15. Archibong-Eso, A.; Aliyu, A.M.; Yan, W.; Okeke, N.E.; Baba, Y.D.; Fajemidupe, O.; Yeung, H. Experimental study on sand transport characteristics in horizontal and inclined two-phase solid-liquid pipe flow. J. Pipeline Syst. Eng. Pract. 2020, 11, 04019050. [CrossRef]

16. Xu, Z.; Wu, J.; Li, H.; Chen, Y.; Xu, J.; Xiong, L.; Zhang, J. Characterizing heavy metals in combined sewer overflows and its influence on microbial diversity. Sci. Total Environ. 2018, 625, 1272-1282. [CrossRef]

17. Ashley, R.M.; Arthur, S.; Coghlan, B.P.; McGregor, I. Fluid sediment in combined sewers. Water Sci. Technol. 1994, 29, 113-123. [CrossRef]

18. Skipworth, P.J.; Tait, S.J.; Saul, A.J. Erosion of sediment beds in sewers: Model development. J. Environ. Eng. 1999, 125, 566-573. [CrossRef]

19. Schertzinger, G.; Itzel, F.; Kerstein, J.; Tuerk, J.; Schmidt, T.C.; Sures, B. Accumulation pattern and possible adverse effects of organic pollutants in sediments downstream of combined sewer overflows. Sci. Total Environ. 2019, 675, 295-304. [CrossRef]

20. Caviedes-Voullième, D.; Morales-Hernández, M.; Juez, C.; Lacasta, A.; García-Navarro, P. Two-dimensional numerical simulation of bed-load transport of a finite-depth sediment layer: Applications to channel flushing. J. Hydraul. Eng. 2017, 143, 04017034. [CrossRef]

21. Rinas, M.; Tränckner, J.; Koegst, T. Sediment Transport in Sewage Pressure Pipes, Part I: Continuous Determination of Settling and Erosion Characteristics by In-Situ TSS Monitoring Inside a Pressure Pipe in Northern Germany. Water 2019, 11, 2125. [CrossRef]

22. Einstein, H.A. Formula for the transportation of bed load. Transp. ASCE 1942, 107, 561-573.

23. Meyer-Peter, E.; Müller, R. Formulas for bed-load transport. In IAHSR 2nd Meeting; IAHR: Stockholm, Sweden, 1948; Appendix 2; pp. 39-64.

24. Brown, C.B. Sediment transportation. In Engineering Hydraulics; Rouse, H., Ed.; John Wiley \& Sons: New York, NY, USA, 1950; pp. 769-857.

25. Engelund, F.; Hansen, E. A Monograph on Sediment Transport in Alluvial Streams; Technical University of Denmark: Copenhagen, Denmark, 1967.

26. Ackers, P.; White, W.R. Sediment transport: New approach and analysis. J. Hydraul. Div. 1973, 99, $204-254$.

27. van Rijn, L.C. Principles of Sedimen Transport in Rivers, Estuaries and Coastal Seas; Aqua Publications: Amsterdam, The Netherlands, 1993; Volume 1006.

28. van Rijn, L.C.; Strypsteen, G. A fully predictive model for aeolian sand transport. Coast. Eng. 2020, 156, 103600. [CrossRef]

29. van Rijn, L.C. Erodibility of mud-sand bed mixtures. J. Hydraul. Eng. 2020, 146, 04019050. [CrossRef]

30. Juez, C.; Murillo, J.; García-Navarro, P. Numerical assessment of bed-load discharge formulations for transient flow in 1D and 2D situations. J. Hydroinform. 2013, 15, 1234-1257. [CrossRef]

31. Song, Y.H.; Yun, R.; Lee, E.H.; Lee, J.H. Predicting sedimentation in urban sewer conduits. Water 2018, 10, 462. [CrossRef]

32. Song, Y.H.; Lee, E.H.; Lee, J.H. Functional relationship between soil slurry transfer and deposition in urban sewer conduits. Water 2018, 10, 825. [CrossRef]

33. Launder, B.E.; Spalding, D.B. The numerical computation of turbulent flows. In Numerical Prediction of Flow, Heat Transfer, Turbulence and Combustion; Pergamon Press: New York, NY, USA, 1983; pp. 96-116.

34. Versteeg, H.K.; Malalasekera, W. An Introduction to Computational Fluid Dynamics: The Finite Volume Method; Pearson Education: London, UK, 2007.

35. Zhu, X.; Chatain, V.; Gautier, M.; Blanc-Biscarat, D.; Delolme, C.; Dumont, N.; Aubin, J.-B.; Kouyi, G.L. Combination of Lagrangian Discrete Phase Model and sediment physico-chemical characteristics for the prediction of the distribution of trace metal contamination in a stormwater detention basin. Sci. Total Environ. 2020, 698, 134263. [CrossRef]

36. Baalisampang, T.; Abbassi, R.; Garaniya, V.; Khan, F.; Dadashzadeh, M. Fire impact assessment in FLNG processing facilities using Computational Fluid Dynamics (CFD). Fire Saf. J. 2017, 92, 42-52. [CrossRef]

37. Campisano, A.; Modica, C.; Creaco, E.; Shahsavari, G. A model for non-uniform sediment transport induced by flushing in sewer channels. Water Res. 2019, 163, 114903. [CrossRef] [PubMed] 
38. Heinl, E.; Bohnet, M. Calculation of particle-wall adhesion in horizontal gas-solids flow using CFD. Powder Technol. 2015, 159, 95-104. [CrossRef]

39. Kaushal, D.R.; Thinglas, T.; Tomita, Y.; Kuchii, S.; Tsukamoto, H. CFD modeling for pipeline flow of fine particles at high concentration. Int. J. Multiph. Flow 2012, 43, 85-100. [CrossRef]

40. ANSYS. ANSYS Fluent 12.1 Theory Guide; ANSYS Inc.: Canonsburg, PA, USA, 2010.

41. Park, C.W.; Hong, C.H. User Guide of ANSYS Workbench; Intervision: Seoul, Korea, 2008.

42. Everitt, B.S.; Hand, D. Finite Mixture Distributions; Wiley \& Sons, Inc.: London, UK, 1985.

43. Nabil, T.; EL-Sawaf, I.; EL-Nahhas, K. Sand-water slurry flow modelling in a horizontal pipeline by computational fluid dynamics technique. Int. Water Technol. J. 2014, 4, 1-17.

44. Ota, J.J.; Perrusquia, G. Particle velocity and sediment transport at limit deposition in sewers. In Proceedings of the 12th International Conference on Urban Drainage, Porto Alegre/RS, Brazil, 11-16 September 2011; pp. 1-8.

45. Kim, C.H.; Han, C.H. Numerical simulation of hydraulic transport of soil-water mixtures in pipelines. Open J. Fluid Dyn. 2013, 3, 266-270. [CrossRef]

46. Anjum, N.; Ghani, U.; Ahmed Pasha, G.; Latif, A.; Sultan, T.; Ali, S. To investigate the flow structure of discontinuous vegetation patches of two vertically different layers in an open channel. Water 2018, 10, 75. [CrossRef]

47. Török, G.T.; Baranya, S.; Rüther, N. 3D CFD modeling of local scouring, bed armoring and sediment deposition. Water 2017, 9, 56. [CrossRef]

48. Fan, F.; Liang, B.; Li, Y.; Bai, Y.; Zhu, Y.; Zhu, Z. Numerical investigation of the influence of water jumping on the local scour beneath a pipeline under steady flow. Water 2017, 9, 642. [CrossRef]

49. Hanjalić, K.; Launder, B.E. A Reynolds stress model of turbulence and its application to thin shear flows. J. Fluid Mech. 1972, 52, 609-638. [CrossRef]

50. Matousek, V. Flow Mechanism of Soil-Water Mixtures in Pipelines. Ph.D. Thesis, Delft University, Delft, The Netherlands, 15 December 1997.

51. Liu, Z. Sediment Transport; Aalborg Universitet: Aalborg, Denmark, 2001.

52. Butler, D.; May, R.; Ackers, J. Self-cleansing sewer design based on sediment transport principles. J. Hydraul. Eng. 2004, 130, 723. [CrossRef]

53. Raudkivi, A.J. Loose Boundary Hydraulics; CRC Press: Boca Raton, FL, USA, 1998.

54. Nezu, I. Experimental Study on Secondary Currents in Open Channel Flows. In Proceedings of the 21st IAHR Congress, Melbourne, Australia, 13-18 August 1985.

55. Nezu, I.; Nakagawa, H.; Jirka, G.H. Turbulence in open-channel flows. J. Hydraul. Eng. 1994, 120, $1235-1237$. [CrossRef]

56. Martinuzzi, R.; Pollard, A. Comparative study of turbulence models in predicting turbulent pipe flow. I-Algebraic stress and k-epsilon models. AIAA J. 1989, 27, 29-36. [CrossRef]

57. Pollard, A.; Martinuzzi, R. Comparative study of turbulence models in predicting turbulent pipe flow. II-Reynolds stress and k-epsilon models. AIAA J. 1989, 27, 1714-1721. [CrossRef]

58. Wilcox, D.C. Turbulence Modeling for CFD; DCW Industries: La Canada, CA, USA, 1998; Volume 2, pp. $172-180$.

59. Bjørlykke, K.; Middleton, G.V. Compaction (consolidation) of sediments. In Encyclopedia of Sediments and Sedimentary Rocks; Kluwer Academic Publishers: Dordrecht, The Netherlands, 2003; pp. 161-168.

60. Gisselbrecht, M.; Plaut, E. High Reynolds number K-epsilon model of turbulent pipe flows with standard wall laws: First quantitative results. In 22ème Congrès Français de Mécanique 2015; HAL: Lyon, France, 2015.

61. Singh, K.P.; Kumar, A.; Kaushal, D.R. CFD modelling and experimental investigation of bimodal slurry flow in horizontal pipeline and bends. In Advances in Fluid and Thermal Engineering; Springer: Singapore, 2019; pp. 337-345.

62. Zhiyao, S.; Tingting, W.; Fumin, X.; Ruijie, L. A simple formula for predicting settling velocity of sediment particles. Water Sci. Eng. 2008, 1, 37-43. [CrossRef]

63. Guo, S.J.; Zhang, F.H.; Song, X.G.; Wang, B.T. Deposited sediment settlement and consolidation mechanisms. Water Sci. Eng. 2015, 8, 335-344. [CrossRef]

(C) 2020 by the authors. Licensee MDPI, Basel, Switzerland. This article is an open access article distributed under the terms and conditions of the Creative Commons Attribution (CC BY) license (http://creativecommons.org/licenses/by/4.0/). 